\title{
On Min - Cs Modules and Some Related Concepts
}

\author{
Inaam Mohammed Ali Hadi* \\ Rana Noori Majeed $* *$
}

Received 20, December, 2012

Accepted 3, March, 2014

\begin{abstract}
:
Our aim in this paper is to study the relationships between min-cs modules and some other known generalizations of cs-modules such as ECS-modules, Pextending modules and n-extending modules. Also we introduce and study the relationships between direct sum of mic-cs modules and mc-injectivity.
\end{abstract}

Key words: CS-module, min-CS module, mc-injectivity.

\section{1- Introduction}

Throughout this paper all rings $\mathrm{R}$ are commutative with identity and all R-modules are unitary. We write $\mathrm{A} \leq$ $\mathrm{M}$ to indicate that $\mathrm{A}$ is a submodule of M.

A submodule $\mathrm{N} \leq \mathrm{M}$ is called essential in $\mathrm{M}$ (denoted by $\mathrm{N} \leq_{e} \mathrm{M}$ ) if for each $\mathrm{W} \leq \mathrm{M}, \mathrm{N} \cap \mathrm{W}=(0)$ implies $\mathrm{W}=(0) \cdot[1, \mathrm{p} .15]$

A submodule $\mathrm{N}$ of $\mathrm{M}$ is called closed if $\mathrm{N}$ has no proper essential submodule extension in $\mathbf{M}$; that is if $\mathrm{N} \leq{ }_{\mathrm{e}} \mathrm{W}$ for some $\mathrm{W} \leq \mathrm{M}$, then $\mathrm{N}=\mathrm{W}$. it is clear that $\mathrm{M},(0)$ are closed submodules.

An $\mathrm{R}$-module $\mathrm{M}$ is called an extending module (or, CS-module) if every submodule is an essential in a direct summand of M. Equivalently, every closed submodule is a direct summand, [2, P.55]

A nonzero submodule $\mathrm{N}$ of $\mathrm{M}$ is called a minimal closed submodule if there is no nonzero closed submodule $\mathrm{W}$ of $\mathrm{M}$ such that $\mathrm{W} \subseteq \mathrm{N}$. For example, $\langle\overline{2}\rangle$ and $\langle\overline{3}\rangle$ are minimal closed submodules in a $\quad \mathbb{Z}$-module $\mathbb{Z}_{6}$, also $\langle\overline{3}>$ and $\langle\overline{4}>$ are minimal closed submodules in $\mathbb{Z}_{12}$ as a $\mathbb{Z}$-module.

An R-module $\mathrm{M}$ is called min-CS submodules are direct summand of $\mathrm{M}$ [3].

It is clear that every CS-module is min-CS module, but not conversely.

For more details about min-CS module, see [4].

Recall that an ec-closed submodule $\mathrm{N}$ of an $\mathrm{R}$-module $\mathrm{M}$, is a closed submodule which contains essentially a cyclic submodule [5].

\section{Lemma (1.1):}

Let $U$ be a minimal closed submodule of an R-module M. Then U is an ec-closed submodule.

Proof:

Since $U$ is a minimal closed submodule of $\mathrm{M}$, then $\mathrm{U}$ is a uniform closed submodule, by [4, lemma (2.1.6), p.24] Thus for each $\mathrm{x} \in \mathrm{U}$ we have $<\mathrm{x}>\leq_{\mathrm{e}} \mathrm{U}$.

Hence $\mathrm{U}$ is an ec-closed submodule.

Recall that an ECS R-module M is a module such that every ec-closed submodule is a direct summand [5].

\section{Proposition (1.2):}

Every ECS-R-module is min-CS. Proof: module if all minimal closed

*Department of Mathematics-Ibn-Al-Haitham College of Education for purescience - University of Baghdad

**Ibn-Al-Haitham College of Education for purescience - University of Baghdad 
Let $\mathrm{M}$ be an ECS-module, and let $\mathrm{U}$ be a minimal closed submodule of M.

So by lemma (1.1) U is an ec-closed submodule.

Hence $U$ is a direct summand of $M$, since $\mathrm{M}$ is an ECS-module. Thus $\mathrm{M}$ is a min-CS module.

Recall that, R-module $\mathrm{M}$ has uniform dimension (briefly U-dim) if $M$ does not contain an infinite direct sum of nonzero submodules.

Equivalently, $\mathrm{M}$ is contains an essential submodule of the form $\mathrm{U} 1 \oplus$ $\ldots \oplus$ Un for some uniform submodule $\mathrm{Ui} \subseteq \mathrm{M}$.

If no such integer $\mathrm{n}$ exists, we write $\mathrm{U}$-dim $=\infty$; that is $\mathrm{M}$ contains an infinite direct sum of nonzero submodules, see [6, proposition 6.4].

Another name used for the uniform dimension is Goldie dimension (or Goldie rank), named after its discover. We prefer the term "uniform dimension" since the uniform modules play a key rule in its definition.

Also Goodearl, see [p.79, p.86], gave the name finite dimensional module for module with finite uniform dimension.

It is easy to check that U-dim $\mathrm{M}=$ 0 if and only if $\mathrm{M}=0$ and $\mathrm{U}-\operatorname{dim} \mathrm{M}=$ 1 if and only if $\mathrm{M}$ is a uniform module.

The following result is given in [5, proposition 1.2, p.1249].

\section{Proposition (1.3):}

Let $M$ be a module with finite uniform dimension. Then $\mathrm{M}$ is a CS module if and only if $\mathrm{M}$ is an ECS module. result:

Hence we can give the following

\section{Corollary (1.4):}

Let $\mathrm{M}$ be an R-module with a finite uniform dimension. Then the following statements are equivalent:

$\mathrm{M}$ is a CS-module.

$\mathrm{M}$ is an ECS-module.

$\mathrm{M}$ is a min-CS module.

Proof:

$(1) \Leftrightarrow(2)$ : It follows by proposition (1.3).

$(1) \Leftrightarrow(3)$ : It follows by [4, corollary (2.2.19), p.57].

\section{Corollary (1.5):}

Let $M$ be a Noetherian (or Artinian) R-module. Then the following statements are equivalent:

$\mathrm{M}$ is a CS-module.

$\mathrm{M}$ is an ECS-module.

$\mathrm{M}$ is a min-CS module.

Proof:

(1.4), since every Noetherian (Artinian) module has a finite uniform dimension, by [6, corollary 6.7, p.211].

Also, we have the following:

\section{Corollary (1.6):}

Let $\mathrm{R}$ be a Goldie ring. Then the following statements are equivalent:

$\mathrm{R}$ is a min-CS ring.

$\mathrm{R}$ is an ECS-ring.

$\mathrm{R}$ is a CS-ring.

Proof:

Since a Goldie ring $\mathrm{R}$ has a finite uniform dimension.

Hence the result follows directely by corollary (1.4).

\section{Example (1.7):}

Let $\mathrm{M}=\mathrm{Q} \oplus \mathbb{Z} \mathrm{p}$ as a $\mathbb{Z}$-module, where $\mathrm{p}$ is any prime integer.

$\mathrm{M}$ is not CS-module, by[4, examples (2.2.25(1)), p.61].

Since $M$ has a finite uniform dimension, $\mathrm{M}$ is not min-CS and $\mathrm{M}$ is not ECS, by corollary (1.4). 


\section{Example (1.8): [5, p.1248]}

Let $\mathrm{R}$ be a ring such that $\mathrm{R}=\left[\begin{array}{cc}\mathbb{Z}_{2} & \mathbb{Z}_{2} \\ 0 & \mathbb{Z}\end{array}\right]$ , $\mathrm{R}$ is not CS by [ 5 ,p.1248].

Since $\mathrm{R}$ has finite uniform dimension, $\mathrm{R}$ is not min-CS and R is not ECS by corollary (1.4).

Recall that, an R-module $\mathrm{M}$ is called a P-extending module if every cyclic submodule of $M$ is essential in a direct summand of $\mathrm{M}$, [7].

\section{Proposition (1.9):}

Let $\mathrm{M}$ be a nonsingular module with finite uniform dimension. Then the following statements are equivalent:

(1) M is CS.

(2) $\mathrm{M}$ is ECS.

(3) $\mathrm{M}$ is P-extending.

(4) $\mathrm{M}$ is min-CS.

Proof:

$(1) \Leftrightarrow(2)$ : It follows by [5, proposition 1.2(iii)].

(2) $\Leftrightarrow(3)$ : It follows by [5, proposition 1.2(i)].

(1) $\Leftrightarrow$ (4): It follows by [4, corollary (2.2.19), p.57].

Now, we have the following

\section{Lemma (1.10):}

Let $\mathrm{M}$ be an indecomposable $\mathrm{R}$ module with uniform submodule. If $M$ is ECS then M is uniform.

Proof:

Let $\mathrm{M}$ be an ECS-module. Then by proposition (1.2), $\mathrm{M}$ is a min-CS module.

Hence the result follows by [4, corollary (2.1.12), p.27].

\section{Proposition (1.11):}

Let $\mathrm{M}$ be an indecomposable $\mathrm{R}$ module with uniform submodule. Then the following statements are equivalent:
(1)M is a min-CS module.

(2) $\mathrm{M}$ is a uniform module.

(3) $\mathrm{M}$ is a CS-module.

(4) $\mathrm{M}$ is an ECS-module.

Proof:

$(1) \Leftrightarrow(2)$ : It follows by [4, corollary (2.1.12), p.27].

(2) $\Leftrightarrow(3)$ : It is clear.

(3) $\Leftrightarrow(1)$ : It is clear.

(4) $\Leftrightarrow$ (2): It follows by proposition (1.10).

Recall that an $\mathrm{R}$-module $\mathrm{M}$ is called n-extending if every closed submodule $\mathrm{A}$ of $\mathrm{M}$ (with a $\mathrm{U}-\operatorname{dim}(\mathrm{A}) \leq$ $\mathrm{n}$ ) is a direct summand of $\mathrm{M}$.

Or equivalently:

Every submodule A of $\mathrm{M}$ (with $\mathrm{U}$ $-\operatorname{dim}(\mathrm{A}) \leq \mathrm{n})$ is essential in a direct summand of $\mathrm{M}$, [7].

To prove the following result we need the following lemma which appeared in [8, proposition 4]. However we give a different proof.

\section{Lemma (1.12):}

Let $\mathrm{M}$ be an R-module. If $\mathrm{M}$ is 1extending module then $M$ is $n$ extending module, for each $n \in \mathbb{Z}_{+}$. Proof:

The proof is by induction.

Assume, for any submodule $\mathrm{V}$ of $\mathrm{M}$ with $\operatorname{dim}(\mathrm{V})<\mathrm{n}, \quad \mathrm{V}$ is a direct summand. Let $\mathrm{K}$ be a closed submodule of $\mathrm{M}$ with $\mathrm{U}-\operatorname{dim}=\mathrm{n}$ such that $\mathrm{n}>1$. Since $\mathrm{K}$ has a finite uniform dimension.

Then $\mathrm{K}$ has a uniform closed submodule $\mathrm{U}$, by $[4$, proposition (1.62), p.17].

So $\operatorname{dim}(U)<\operatorname{dim}(K)=n$, by $[1$, proposition 3.18, p.86], [6, proof of proposition .4, p.211].

But $\mathrm{U}$ is closed in $\mathrm{K}$ and $\mathrm{K}$ is closed in M. So we get $U$ is closed in $M$, by [1, proposition (1.5), p18].

Then by induction, $U$ is a direct summand of $\mathrm{M}$; that is $\mathrm{M}=\mathrm{U} \oplus \mathrm{U}^{\prime}$ for some $\mathrm{U}^{\prime} \leq \mathrm{M}$. 
Hence $\mathrm{K}=\mathrm{K} \cap\left(\mathrm{U} \oplus \mathrm{U}^{\prime}\right)$ and $\mathrm{U} \leq \mathrm{K}$. Thus $\mathrm{K}=\mathrm{U} \oplus\left(\mathrm{K} \cap \mathrm{U}^{\prime}\right)$ by modular law.

This implies $\mathrm{K} \cap \mathrm{U}^{\prime}$ is closed in $\mathrm{K}$.

But $\mathrm{K}$ has a finite uniform dimension.

Hence $\operatorname{dim}\left(\mathrm{K} \cap \mathrm{U}^{\prime}\right)<\operatorname{dim}(\mathrm{K})=\mathrm{n}$, by [6, theorem 6.37, p.219], [2, 5-10, p.41].

Since $\mathrm{K} \cap \mathrm{U}^{\prime}$ is closed in $\mathrm{K}$ and $\mathrm{K}$ is closed in $\mathrm{M}$, then $\mathrm{K} \cap \mathrm{U}^{\prime}$ is closed in $\mathrm{M}$, by [1, proposition (1.5), p18].

It follows that $\mathrm{K} \cap \mathrm{U}^{\prime}$ is a direct summand of $\mathrm{M}$, by induction.

Hence $\mathrm{M}=\left(\mathrm{K} \cap \mathrm{U}^{\prime}\right) \oplus \mathrm{W}$ for some $\mathrm{W}$ $\leq \mathrm{M}$. Which implies that $\mathrm{U}^{\prime}=\mathrm{U}^{\prime} \cap[(\mathrm{K}$ $\left.\left.\cap \mathrm{U}^{\prime}\right) \oplus \mathrm{W}\right]$.

But $\mathrm{K} \cap \mathrm{U}^{\prime} \subseteq \mathrm{U}^{\prime}$, then by modular law $\mathrm{U}^{\prime}=(\mathrm{K} \cap \mathrm{U}) \oplus\left(\mathrm{W} \cap \mathrm{U}^{\prime}\right)$.

On the other hand $\mathrm{M}=\mathrm{U} \oplus \mathrm{U}^{\prime}$.

This implies that

$$
\begin{aligned}
\mathrm{M} & =\mathrm{U} \oplus\left[\left(\mathrm{K} \cap \mathrm{U}^{\prime}\right) \oplus\left(\mathrm{W} \cap \mathrm{U}^{\prime}\right)\right] \\
& =\left[\mathrm{U} \oplus\left(\mathrm{K} \cap \mathrm{U}^{\prime}\right)\right] \oplus\left(\mathrm{W} \cap \mathrm{U}^{\prime}\right) \\
& =\mathrm{K} \oplus\left(\mathrm{W} \cap \mathrm{U}^{\prime}\right) .
\end{aligned}
$$

Thus $\mathrm{K}$ is a direct summand of $\mathrm{M}$.

Now, we will prove that under the class of finite uniform dimension each of the following modules are equivalent to a min-CS module: CSmodules, 1-extending modules, and ECS-modules.

\section{Theorem (1.13):}

Let $M$ be a module with finite uniform dimension. Then the following statements are equivalent:

$\mathrm{M}$ is CS-module.

$\mathrm{M}$ is 1-extending module.

$M$ is ECS-module.

$\mathrm{M}$ is min-CS module.

Proof:

(1) $\Leftrightarrow$ (3) $\Leftrightarrow$ (4) : It follows by corollary (1.4).

$(1) \Rightarrow(2)$ : It is clear.

(2) $\Rightarrow$ (1) Let $\mathrm{M}$ be a 1-extending module. To prove $\mathrm{M}$ is CS-module.

Let $\mathrm{C}$ be a closed submodule of $\mathrm{M}$.

Since $M$ has a finite uniform dimension.
Then $\mathrm{C}$ has a finite uniform dimension by $[6$, theorem 6.37, p.219], [2, 5-10, p.41].

But $\mathrm{M}$ is 1-extending module, then by lemma (1.12), $\mathrm{M}$ is n-extending for each $n \in \mathbb{N}$.

Hence $\mathrm{C}$ is a direct summand. Thus $\mathrm{M}$ is a CS-module.

Now we introduce the following definitions

\section{Definition (1.14):}

Let $\mathrm{M}_{1}$ and $\mathrm{M}_{2}$ be R-modules. $\mathrm{M}_{1}$ is called $\mathrm{M}_{2}$-mc-injective if for each minimal closed submodule $\mathrm{N}$ of $\mathrm{M}_{2}$ and for each R-homomorphism map f: $\mathrm{N} \longrightarrow \mathrm{M}_{1}$ can be extended $\mathrm{f}$ ': $\mathrm{M}_{2}$ $\longrightarrow \mathrm{M}_{1}$

$$
\mathrm{N} \stackrel{\mathrm{i}}{\longrightarrow} \mathrm{M}_{2}
$$

$\mathrm{f} \square \quad \square \mathrm{f}^{\prime}$

$\mathrm{M}_{1}$

$\mathrm{f}^{\prime} \circ \mathrm{i}=\mathrm{N}$ where $\mathrm{i}$ is the inclusion map.

\section{Definition (1.15):}

Let $\mathrm{M}_{1}$ and $\mathrm{M}_{2}$ be R-modules. $\mathrm{M}_{1}$ and $\mathrm{M}_{2}$ are said to be mutually mcinjective if $\mathrm{M}_{1}$ is $\mathrm{M}_{2}$-mc-injective and $\mathrm{M}_{2}$ is $\mathrm{M}_{1}$-mc-injective.

To prove the next theorem, we need the following lemma, compare with [2, lemma 7.5, p.57].

\section{Lemma (1.16):}

Let $\mathrm{M}$ be an $\mathrm{R}$-module such that $\mathrm{M}=\mathrm{M}_{1} \oplus \mathrm{M}_{2}$, where $\mathrm{M}_{1}$ and $\mathrm{M}_{2}$ are submodules of $\mathrm{M}$. Then $\mathrm{M}_{1}$ is $\mathrm{M}_{2}$-mcinjective if and only if for each minimal closed submodule $\mathrm{N}$ of $\mathrm{M}$ such that $\mathrm{N} \cap \mathrm{M}_{1}=0$ there exists $\mathrm{A} \leq$ $\mathrm{M}, \mathrm{N} \leq \mathrm{A}$ and $\mathrm{M}=\mathrm{M}_{1} \oplus \mathrm{A}$.

Proof:

$(\Rightarrow)$ Let $\mathrm{N}$ be a minimal closed submodule of $\mathrm{M}$ such that $\mathrm{N} \cap \mathrm{M}_{1}=0$. Let $\pi_{1}: \mathrm{M} \longrightarrow \mathrm{M}_{1}$ and $\pi_{2}: \mathrm{M} \longrightarrow \mathrm{M}_{2}$ be the natural projection maps. 
Let g: $\pi_{1} \mid \mathrm{N}$ and $\beta: \pi_{2} \mid \mathrm{N}$.

Since $\mathrm{M}_{1}$ is $\mathrm{M}_{2}$-mc-injective, there exists a homomorphism $\mathrm{f}: \mathrm{M}_{2} \longrightarrow \mathrm{M}_{1}$ such that $\mathrm{f} \circ \beta=\mathrm{g}$.

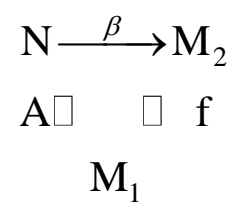

Let $L=\left\{f(m)+m\right.$ such that $\left.m \in M_{2}\right\}$. This implies $\mathrm{N} \leq \mathrm{L}$ and $\mathrm{M}=\mathrm{M}_{1} \oplus \mathrm{L}$.

To show this:

Let $\mathrm{x} \in \mathrm{M}_{1} \cap \mathrm{L}$, then $\mathrm{x} \in \mathrm{M}_{1}$ and $\mathrm{x} \in$ L. Then $\mathrm{x}-\mathrm{f}(\mathrm{m})=0, \mathrm{~m}=0$; hence $\mathrm{x}=$ $\mathrm{f}(\mathrm{m})=\mathrm{f}(0)=0$.

This implies that $\mathrm{M}_{1} \cap \mathrm{L}=0$.

Now, to prove $\mathrm{M}=\mathrm{M}_{1} \oplus \mathrm{L}$.

Let $m \in M$, then $m=m_{1}+m_{2}$ such that $\mathrm{m}_{1} \in \mathrm{M}_{1}$ and $\mathrm{m}_{2} \in \mathrm{M}_{2}$.

But $\mathrm{m}=\left(\mathrm{m}_{1}-\mathrm{f}\left(\mathrm{m}_{2}\right)\right)+\left(\mathrm{f}\left(\mathrm{m}_{2}\right)+\mathrm{m}_{2}\right) \in$ $\mathrm{M}_{1}+\mathrm{L}$.

Thus $\mathrm{M}=\mathrm{M}_{1} \oplus \mathrm{L}$.

To prove $\mathrm{N} \leq \mathrm{L}$.

Let $\mathrm{n} \in \mathbb{N}$ so $\mathrm{n}=\mathrm{a}+\mathrm{b}$ for some $\mathrm{a} \in$ $\mathrm{M}_{1}$ and $\mathrm{b} \in \mathrm{M}_{2}$.

Since $\beta(\mathrm{n}) \in \mathrm{M} 2$, then $\mathrm{f}(\beta(\mathrm{n}))+\beta(\mathrm{n}) \in$ L.

Hence $\mathrm{g}(\mathrm{n})+\beta(\mathrm{n}) \in \mathrm{L}$, since $\mathrm{f} \circ \beta=\mathrm{g}$. But g: $\pi_{1} \mid \mathrm{N}$ and $\beta: \pi_{2} \mid \mathrm{N}$, we have $\mathrm{g}(\mathrm{n})=\mathrm{g}(\mathrm{a}+\mathrm{b})=\mathrm{a}$ and $\beta(\mathrm{n})=\beta(\mathrm{a}+$ $\mathrm{b})=\mathrm{b}$; it follows that $\mathrm{g}(\mathrm{n})+\beta(\mathrm{n})=\mathrm{a}+$ $\mathrm{b}=\mathrm{n}$.

Thus $\mathrm{n} \in \mathrm{L}$.

$(\Leftarrow)$ Let $\mathrm{S}$ be a minimal closed submodule of $\mathrm{M}_{2}$, and let $\mathrm{f}: \mathrm{S} \longrightarrow \mathrm{M}_{1}$. To extend $\mathrm{f}$ into $\mathrm{f}^{\prime}: \mathrm{M}_{2} \longrightarrow \mathrm{M}_{1}$.

Put $\mathrm{H}=\{-\mathrm{f}(\mathrm{s})+\mathrm{s}$ such that $\mathrm{s} \in \mathrm{S}\}$.

Hence, there exists g: $\mathrm{S} \longrightarrow \mathrm{H}$ defined by $\mathrm{g}(\mathrm{s})=-\mathrm{f}(\mathrm{s})+\mathrm{s}$, and $\mathrm{g}$ is an isomorphism.

Hence $\mathrm{S}$ is isomorphic to $\mathrm{H}$. Hence $\mathrm{H}$ is minimal closed in $\mathrm{M}_{2}$.

But $\mathrm{H}$ is closed submodule in $\mathrm{M}_{2}$ and $\mathrm{M}_{2}$ closed in $\mathrm{M}$, imply $\mathrm{H}$ is closed in $\mathrm{M}$, by [1, proposition (1.5), p18].

Suppose there exists $\mathrm{K}$ is closed in $\mathrm{M}$ such that $\mathrm{K} \subseteq \mathrm{H}$.

Since $\mathrm{H} \subseteq \mathrm{M}_{2}, \mathrm{~K} \subseteq \mathrm{M}_{2}$.
But $\mathrm{K} \subseteq \mathrm{M}_{2}$ and $\mathrm{K}$ is closed in $\mathrm{M}$.

Thus $\mathrm{K}$ is closed in $\mathrm{M}_{2}$, by [1, p.18].

Thus $\mathrm{H}=\mathrm{K}$ since $\mathrm{H}$ is minimal closed in $\mathrm{M}_{2}$.

Therefore $\mathrm{K}$ is a minimal closed in $\mathrm{M}$.

We can show that $\mathrm{H} \cap \mathrm{M}_{1}=0$; for this let $\mathrm{x} \in \mathrm{H} \cap \mathrm{M}_{1}$.

Then $\mathrm{x} \in \mathrm{H}$ and $\mathrm{x} \in \mathrm{M}_{1}, \mathrm{x} \in \mathrm{H}$ implies that $\mathrm{x}=-\mathrm{f}(\mathrm{s})+\mathrm{s}$ for some $\mathrm{s} \in \mathrm{M}_{2}$.

So $x+f(s)=s \in M_{1} \cap M_{2}=0$. Then we get $\mathrm{s}=0$ and $\mathrm{x}=-\mathrm{f}(\mathrm{s})=-\mathrm{f}(0)=0$.

Thus $\mathrm{H} \cap \mathrm{M}_{1}=0$.

By hypothesis, there exists $\mathrm{A} \leq \mathrm{M}$ such that $\mathrm{H} \leq \mathrm{A}$ and $\mathrm{M}=\mathrm{M}_{1} \oplus \mathrm{A}$.

Let $\pi: \mathrm{M}_{1} \oplus \mathrm{A} \longrightarrow \mathrm{M}_{1}$ be the natural projection.

It follows that ker $\pi=\{\mathrm{m} \in \mathrm{M} ; \pi(\mathrm{m})=$ $0\}$.

But $\mathrm{m}=\mathrm{m}_{1}+\mathrm{a}$ for some $\mathrm{m}_{1} \in \mathrm{M}, \mathrm{a} \in$ A.

Thus $\pi(\mathrm{m})=\pi\left(\mathrm{m}_{1}+\mathrm{a}\right)=\mathrm{m}_{1}=0$.

This implies ker $\pi=\mathrm{A}$.

Now, $\mathrm{g}=\left.\pi\right|_{\mathrm{M}_{2}: \mathrm{M}_{2} \longrightarrow \mathrm{M}_{1} \text { is a }}$ homomorphism and for each $\mathrm{s} \in \mathrm{S} \subseteq$ $\mathrm{M}_{2}$.

$\mathrm{g}(\mathrm{s})=\mathrm{g}[\mathrm{f}(\mathrm{s})+(-\mathrm{f}(\mathrm{s})+\mathrm{s})]$

$$
=\mathrm{g}(\mathrm{f}(\mathrm{s}))+\mathrm{g}(-\mathrm{f}(\mathrm{s})+\mathrm{s})
$$

Since $\mathrm{f}(\mathrm{s}) \in \mathrm{M}_{1}$ and $-\mathrm{f}(\mathrm{s})+\mathrm{s} \in \mathrm{H} \leq \mathrm{A}$ $=\operatorname{ker} \pi$.

Then $\mathrm{g}(\mathrm{f}(\mathrm{s}))=\mathrm{f}(\mathrm{s}), \mathrm{g}(-\mathrm{f}(\mathrm{s})+\mathrm{s}))=0$. Thus $\mathrm{g}(\mathrm{s})=\mathrm{f}(\mathrm{s})$. It follows that $\mathrm{g} \circ \mathrm{i}=$ $\mathrm{f}$, where $\mathrm{i}$ is the inclusion mapping from $\mathrm{S}$ to $\mathrm{M}_{2}$.

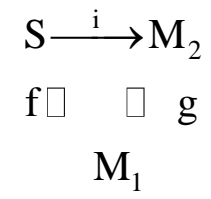

Thus $g=\left.\pi\right|_{M_{2}}$ is an extension of $\mathrm{f}$.

In the following theorem, we give a condition, under which the direct summands of min-CS modules are min-CS modules.

Compare the following result with [2, proposition 7.10, p.59]. 


\section{Theorem (1.17):}

Let $\mathrm{M}$ be an $\mathrm{R}$-module such that $\mathrm{M}=\mathrm{M}_{1} \oplus \mathrm{M}_{2}$ and $\mathrm{M}_{1}$ and $\mathrm{M}_{2}$ are relatively-mc-injective. Then:

$\mathrm{M}_{1}$ and $\mathrm{M}_{2}$ are min-CS modules if and only if $\mathrm{M}$ is a min-CS module.

Proof:

$(\Rightarrow)$ It follows directly by [4, Corollary (2.1.16), p.29].

$(\Leftarrow)$ Let $\mathrm{K}$ be a minimal closed submodule of $\mathrm{M}$. Then by [4, lemma (2.2.3), p.46], $\mathrm{K} \cap \mathrm{M}_{1}=0$ or $\mathrm{K} \cap \mathrm{M}_{2}=0$. Assume $\mathrm{K} \cap \mathrm{M}_{1}=0$, so by lemma (1.16). There exists a submodule $A$ of $M$ such that $\mathrm{M}=\mathrm{M}_{1} \oplus \mathrm{A}$ and $\mathrm{K} \subseteq \mathrm{A}$. Hence $\frac{M}{M_{1}} \cong M_{1} \oplus A$ which is equivalent to

A by second isomorphism theorem.

But $\left(\mathrm{M} / \mathrm{M}_{1}\right)$ equivalent to $\mathrm{M}_{2}$. Thus $\mathrm{M}_{2}$ equivalent to $\mathrm{A}$.

On the other hand, $\mathrm{M}_{2}$ is a min-CS module, hence $\mathrm{A}$ is a min-CS module, by remarks and [4, examples $(2.1 .3$ (10)), p.22].

But $\mathrm{K}$ is a minimal closed of $\mathrm{M}$ and $\mathrm{K}$ $\subseteq \mathrm{A}$, implies $\mathrm{K}$ is a minimal closed of A.

Hence $\mathrm{K}$ is a direct summand of $\mathrm{A}$. Thus $\mathrm{A}=\mathrm{K} \oplus \mathrm{W}$, for some $\mathrm{W} \leq \mathrm{A}$.

Thus $\mathrm{M}=\mathrm{M}_{1} \oplus(\mathrm{K} \oplus \mathrm{W})=\mathrm{K} \oplus\left(\mathrm{M}_{1}\right.$ $\oplus \mathrm{W})$.

Thus $\mathrm{K}$ is a direct summand of $\mathrm{M}$. Hence $\mathrm{M}$ is a min-CS module.

To give our next result, we prove the following lemma:

\section{Lemma (1.18):}

Let $\mathrm{M}$ be an $\mathrm{R}$-module, and $\mathrm{K}$ is a minimal closed submodule of $\mathrm{M}$. If $\mathrm{K}$ is $\mathrm{M}$-mc-injective, then $\mathrm{K}$ is a direct summand of $\mathrm{M}$.

Proof:

Let $\mathrm{i}: \mathrm{K} \longrightarrow \mathrm{K}$ be the identity map.

Since $\mathrm{K}$ is $\mathrm{M}$-mc-injective, then i can be extended to $\theta: \mathrm{M} \longrightarrow \mathrm{K}$.
Thus $\mathbf{M}=\mathrm{K} \oplus \operatorname{ker} \theta$, as we can see below.

Let $\mathrm{x} \in \mathrm{M}$, then $\theta(\mathrm{x}) \in \mathrm{K}$ and $\mathrm{x}-$ $\theta(\mathrm{x}) \in \operatorname{ker} \theta$ because $\theta(\mathrm{x}-\theta(\mathrm{x}))=\theta(\mathrm{x})-$ $\theta(\mathrm{x})=0$

But $\mathrm{x}=\theta(\mathrm{x})+(\mathrm{x}-\theta(\mathrm{x})) \in \mathrm{K}+\operatorname{ker} \theta$.

Now, let $\mathrm{x} \in \mathrm{K} \cap$ ker $\theta$. Then $\mathrm{x} \in \mathrm{K}$ and $\mathrm{x} \in \operatorname{ker} \theta$ and $\theta(\mathrm{x})=0$.

But $\theta(x)=x$, since $\theta$ is the extension of i on $\mathrm{K}$.

Thus $\mathrm{x}=0$ and $\mathrm{K} \cap \operatorname{ker} \theta=0$.

So that $\mathrm{M}=\mathrm{K} \oplus \operatorname{ker} \theta$.

Thus $\mathrm{K}$ is a direct summand of $\mathrm{M}$.

\section{Proposition (1.19):}

Let $\mathrm{M}$ be an R-module. Then the following statements are equivalent:

(1) $\mathrm{M}$ is a min-CS module.

(2) Every module is M-mc-injective.

(3) Every minimal closed submodule of $\mathrm{M}$ is $\mathrm{M}$-mc-injective.

Proof:

(1) $\Rightarrow(2)$ Let $\mathrm{M}_{1}$ be an R-module and let $\mathrm{K} \leq \mathrm{M}$, such that $\mathrm{K}$ is a minimal closed of $\mathrm{M}$ and let $\alpha: \mathrm{K} \longrightarrow \mathrm{M}_{1}$. To extend $\alpha$ to $\beta: M \longrightarrow M_{1}$.

Since $\mathrm{K}$ is a minimal closed submodule of $\mathrm{M}$.

Then there exists $K^{\prime} \leq M$ such that $K \oplus$ $\mathrm{K}^{\prime}=\mathrm{M}$.

Define $\beta: \mathrm{M} \longrightarrow \mathrm{M}_{1}$ by:

$\beta(x+y)= \begin{cases}\alpha(x) & \text { if } y=0 \\ 0 & \text { otherwise. }\end{cases}$

Where $\mathrm{x} \in \mathrm{K}$ and $\mathrm{y} \in \mathrm{K}^{\prime}$.

Hence $\beta$ is the extension of $\alpha$.

(2) $\Rightarrow$ (3) It is clear.

(3) $\Rightarrow$ (1) It follows by lemma (1.18).

\section{References:}

1. K.R.Goodearl, (1976), "Ring Theory, Nonsingular Rings and Modules ", Marcel Dekker, Inc. NewYork and Basel.

2. N.V.Dung, D.V.Huynh, P.F.Smith and R.Wisbauer, (1994), "Extending Modules", John Wiley and Sons, Inc. New York. 
3. Husain Suleman.S.Al-Hazmi, (2005), "A Study of CS and $\sum$-CS Rings and Modules", Ph.D.Thesis, College of Arts and Sciences of Ohio University.

4. I.M.A.Hadi, R.N.Majeed, (2011), "On Min(Max)-CS Modules", M.Sc. Thesis, Ibn-Al-Haitham College of Education - University of Baghdad.

5. Canan Celep Yücel and Adnan Tercan, (2009), "Modules Whose ECClosed Submodules are Direct Summand", Taiwanese Journal of
Mathematics, August, 13(4), (12471256).

6. T.Y.Lam, (1998), "Lectures on Modules and Rings", Ber Keley, California Springer.

7. M.A.Kamal and O.A.El-Mnophy, 2(2005), "On P-Extending Modules", Acta Math. Univ. Comenianac, LXXIV, (279-286).

8. Mahmoud Ahmed Kamal, (1995), "On The Decomposition and Direct Sums of Modules", Osaka J. Math., 32, (125-133).

\section{حول المجموع المباشر لأصغر مقاسات التوسع مع بعض المفاهيم المرتبطة \\ رنا نوري مجيد*** \\ إنعام محمد علي هادي*

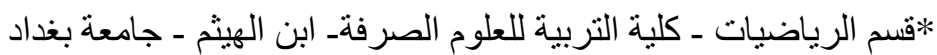

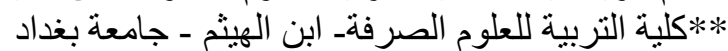

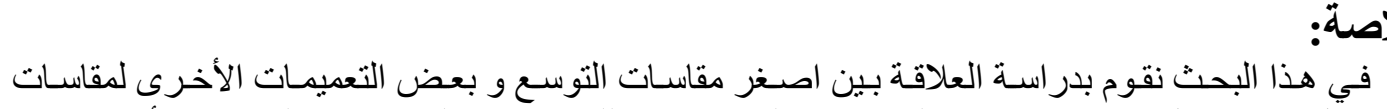

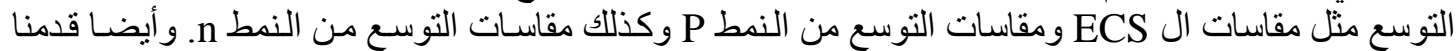

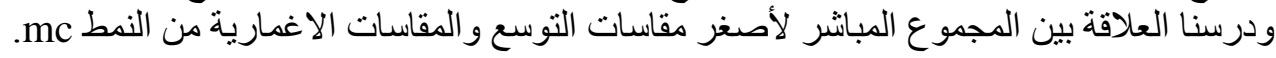

